\title{
Threatened fishes of the world: Sinocyclocheilus anophthalmus (Chen and Chu, 1988) (Cyprinidae)
}

\author{
Yahui Zhao $\cdot$ Chunguang Zhang
}

Received: 17 July 2007 / Accepted: 22 April 2008 / Published online: 23 May 2008

(C) Springer Science + Business Media B.V. 2008

Common name: Blind golden-line barbel. Conservation status: Rare-China Red Data Book of Endangered Animals, Pisces (Yue and Chen 1998); Vulnerable - China Species Red List (Wang and Xie 2004). Identification: D iii, 7; A iii, 5; P i, 15-18; V ii, 8-9. Body almost naked, lateral line scales 46-59. Blind, either eyeless or with small eye dots. Snout blunt, duck-billed. Pectoral fin long, reaching pelvic fin insertion. Living fish generally semi-transparent. Adults reach $113 \mathrm{~mm}$ standard length. Distribution: The fish is only found in Xiaogou Cave in Jiuxiang Town, Yiliang County, Yunnan Province, China, connected to the Xijiang River system. Abundance: Population a few hundred at most (Yue and Chen 1998). Habitat and ecology: The Karst limestone cave is located in altitude $1,638 \mathrm{~m}$ above sea level. Cave water is shallow, around $1 \mathrm{~m}$ deep. Some insects and bats also inhabit the cave. Pieces of insect body parts were detected in stomach contents of fishes. Reproduction: Estimated spawning season is late May or early June. Ripe eggs are about $2 \mathrm{~mm}$ (Chen et al. 1988). Threats: Over-capture was considered to be one of threats (Yue and Chen 1998). Habitat degradation and environmental changes are even more serious, especially from a nearby hydropower station. The very limited distribution puts it at risk for rapid or sudden extinction due to any changes in the

Y. Zhao $(\bowtie) \cdot$ C. Zhang

Institute of Zoology, Chinese Academy of Sciences,

Beijing 100101, People's Republic of China

e-mail: zhaoyh@ioz.ac.cn

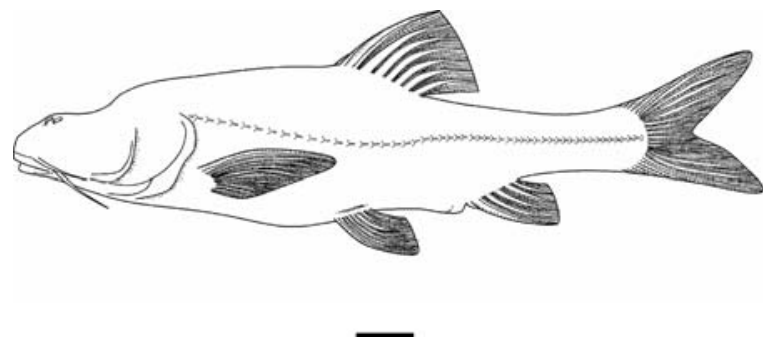

cave. Conservation recommendations: Capture for Sinocyclocheilus anophthalmus should be strictly prohibited except for scientific research. The border of Jiuxiang National Park, currently only a few kilometers away from the cave $S$. anophthalmus inhabits, should be extended to encompass the cave. Effective habitat protection and public awareness programs will be crucial for the survival of this species. Remarks: The conservation status of $S$. anophthalmus was previously underestimated, should be "endangered (EN)". A detailed study of the population dynamics is urgently needed.

\section{References}

Chen YR, Chu XL, Luo ZY, Wu JY (1988) A new blind cyprinid fish from Yunnan, China with reference to the evolution of its characters. Acta Zool Sinica 34:64-70

Wang S, Xie Y (2004) China species red list, vol. 1. Red list. Higher Education Press, Beijing, p 160

Yue PQ, Chen YY (1998) China red data book of endangered animals, Pisces. Science Press, Beijing, pp 107-109 